
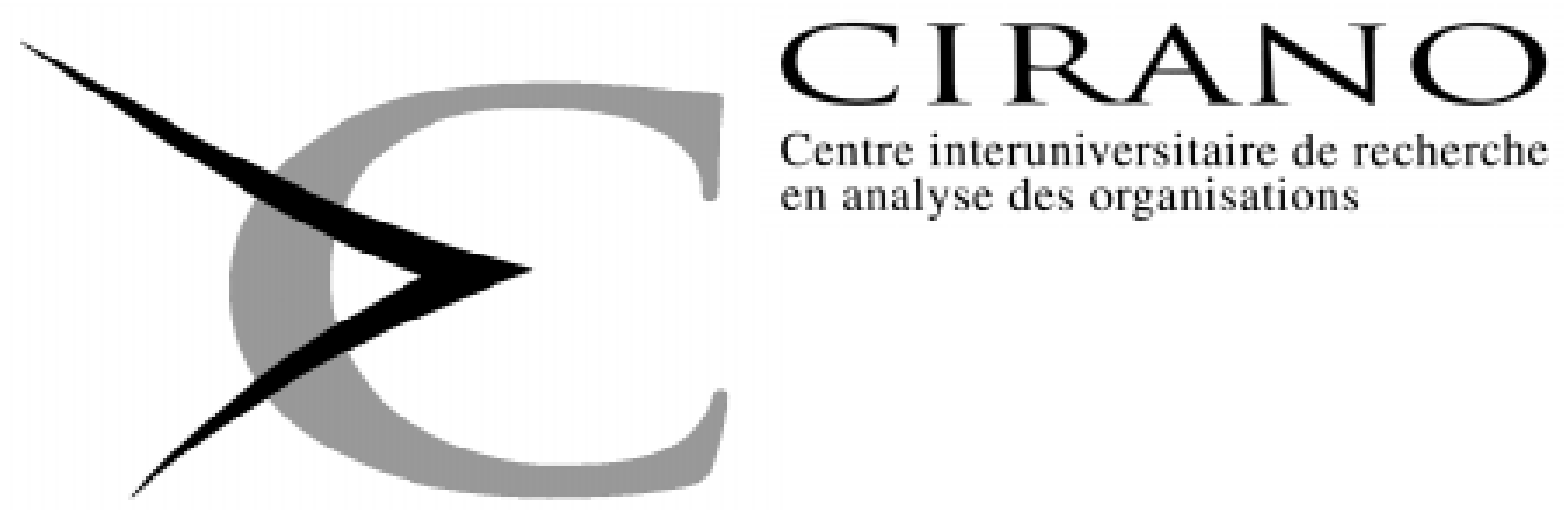

Centre interuniversitaire de recherche en analyse des organisations

Série Scientifique

Scientific Series

97s-22

Comparing Open-Loop with

Markov Equilibria in a

Class of Differential Games

Ngo Van Long, Koji Shimomura,

Harutaka Takahashi 


\section{CIRANO}

Le CIRANO est une corporation privée à but non lucratif constituée en vertu de la Loi des compagnies du Québec. Le financement de son infrastructure et de ses activités de recherche provient des cotisations de ses organisations-membres, d'une subvention d'infrastructure du ministère de l'Industrie, du Commerce, de la Science et de la Technologie, de même que des subventions et mandats obtenus par ses équipes de recherche. La Série Scientifique est la réalisation d'une des missions que s'est données le CIRANO, soit de développer l'analyse scientifique des organisations et des comportements stratégiques.

CIRANO is a private non-profit organization incorporated under the Québec Companies Act. Its infrastructure and research activities are funded through fees paid by member organizations, an infrastructure grant from the Ministère de l'Industrie, du Commerce, de la Science et de la Technologie, and grants and research mandates obtained by its research teams. The Scientific Series fulfils one of the missions of CIRANO: to develop the scientific analysis of organizations and strategic behaviour.

\section{Les organisations-partenaires / The Partner Organizations}

•École des Hautes Études Commerciales

-École Polytechnique

-McGill University

-Université de Montréal

-Université du Québec à Montréal

-Université Laval

-MEQ

-MICST

-Avenor

-Banque Nationale du Canada

-Bell Québec

- Caisse de dépôt et de placement du Québec

-Fédération des caisses populaires Desjardins de Montréal et de l'Ouest-du-Québec

-Hydro-Québec

-Raymond, Chabot, Martin, Paré

-Société d'électrolyse et de chimie Alcan Ltée

-Téléglobe Canada

-Ville de Montréal

Ce document est publié dans l'intention de rendre accessibles les résultats préliminaires de la recherche effectuée au CIRANO, afin de susciter des échanges et des suggestions. Les idées et les opinions émises sont sous l'unique responsabilité des auteurs, et ne représentent pas nécessairement les positions du CIRANO ou de ses partenaires.

This paper presents preliminary research carried out at CIRANO and aims to encourage discussion and comment. The observations and viewpoints expressed are the sole responsibility of the authors. They do not necessarily represent positions of CIRANO or its partners.

ISSN 1198-8177 


\title{
Comparing Open-Loop with Markov Equilibria in a Class of Differential Games*
}

\author{
Ngo Van Long ${ }^{\dagger}$, Koji Shimomura ${ }^{\ddagger}$,Harutaka Takahashi ${ }^{\S}$
}

\section{Résumé / Abstract}

\begin{abstract}
On considère une classe de jeux dynamiques où l'évolution du stock est une fonction hmogène du premier degré. Étant donné un jeu $G$ avec le taux d'actualisation $r$, on considère un équilibre Markov-parfait dont les stratégies sont linéaires par rapport aux variables d'état. On montre que les sentiers des variables de contrôle de cet équilibre constituent un équilibre en boucle ouverte d'un jeu $\hat{G}$ qui correspond à $G$, et qui a un taux d'actualisation $\hat{r}=r+k(k=$ constante $)$. Dans le contexte d'un jeu d'exploitation de ressources naturelles, celà implique que l'équilibre en boucle ouverte tends à conserver les ressources. Alternativement, on considère un jeu $G$ où le taux de dépréciation du stock est $\beta$ et où les stratégies de l'équilibre Markov-parfait sont linéaires. On montre que les sentiers des variables de contrôle donnent un équilibre en boucle ouverte d'un jeu $\widetilde{G}$ dans laquelle le taux de dépréciation du stock est $\tilde{\beta}=\beta+k$. On obtient aussi un résultal dans l'autre direction: sous certaines hypothèses, on peut utiliser un équilibre en boucle ouverte d'un jeu $G$ pour construire un équilibre Markov-parfait d'un jeu modifié $\tilde{G}$.
\end{abstract}

We consider a class of differential games with transition equations that are homogeneous of degree one. For any game $\mathrm{G}$ with a discount rate $\mathrm{r}$, consider a Markov perfect equilibrium (MPE) with strategies that are linear in the state variables. We show that the time paths of the control variables of this equilibrium constitute an open-loop equilibrium of a corresponding game $\mathrm{G}$ that differs from $\mathrm{G}$ only in that its rate of discount $\hat{\mathrm{r}}$ is equal to $\mathrm{r}$ plus a suitably chosen constant. In the context of a resource depletion game, this implies that the open-loop solution is more conservationist. In an alternative formulation, we consider a game $\mathrm{G}$ with a rate of stock depreciation $\beta$, and a Markov perfect equilibrium with strategies that are linear in the state variable. Then the resulting equilibrium time paths of the control variables can be used to form an open-loop equilibrium of a corresponding game $\tilde{\mathrm{G}}$ with a rate of depreciation $\widetilde{\beta}$ that is equal to $\beta$ plus a suitably chosen constant. The interpretation for the

"Correspondence Address: Ngo Van Long, CIRANO, 2020 University Street, 25th floor, Montréal, Qc, Canada H3A 2A5 Tel: (514) 985-4011 Fax: (514) 985-4039 e-mail: longn@ @irano.umontreal.ca The authors are indebted to Gérard Gaudet for comments.

${ }^{\dagger}$ McGill University and CIRANO

Kobe University

$\S$ Meiji Gakuin University 
case of a resource game is similar. We also prove a converse result: under certain assumptions, an open loop equilibrium of a differential game $\mathrm{G}$ can be used to construct a MPE of a modified game $\widetilde{\mathrm{G}}$. This result is useful because it means a MPE can be found by first solving for an open loop equilibrium.

Mots Clés : Jeux différentiels, équilibre Markov-parfait, équilibre en boucle ouverte

Keywords : $\quad$ Differential games, Markov perfect equilibria, open-loop equilibria

JEL : C72, C73, Q30 


\section{INTRODUCTION}

In the differential game litterature there is a time-honoured tradition of comparing open-loop equilibria with closed -loop (or Markov perfect) ones. Fudenberg and Tirole (1991, Sections 4.7 and 13.3) provide a good overview. They offer several reasons why one might be interested in open- loop equlibria. First, these equilibria are relatively more tractable. Second, they "serve as a useful benchmark for discussing the effects of strategic incentives in the closed-loop information structure" (op.cit., p131). Third, if there are many small players, open-loop equilibria are, under certain conditions, good approximation to closed-loop ones. In various examples of differential games involving a common resource stock exploited by several players, it has been observed that open-loop Nash equilibria tend to be more conservationist than Markov Perfect Nash equilibria. See for example Clemhout and Wan (1995). The intuition behind this is that if players use Markovian strategies that specify extraction rates as functions of the current stock size, then each knows that others will extract more, the greater is the current stock size. So each will have little incentive for conservation, and will instead try to reduce the stock at a rate faster than that which he would choose if other players were committed to a given time path of extraction. It seems however that no general theorem of this type has been proved. The purpose of this note is to formalize the above intuition.

We consider a class of differential games with transition equations that are homogeneous of degree one in the control and state variables. Each player has an objective function that is homogeneous of degree $\alpha_{i}$. Under these conditions, it is known (see Long and Shimomura (1995)) that a player's best reply to his opponents' Markovian strategies is homogeneous of degree one in the state variables, if their strategies are homogenous of degree one. Assume there exists a Markov perfect Nash equilibrium with linear strategies for a game $G$ where the rate of discount of player $i$ is $r_{i}$. In Section 2 we show that the resulting time paths of the control variables constitute an open-loop equilibrium of a corresponding game $\hat{G}$ that is identical to $G$ except for the discount rates: the discount rate $\hat{r}_{i}$ in game $\hat{G}$ is equal to $r_{i}$ plus a constant. When this constant is positive, which is the case in resource depletion games, this result implies that open-loop Nash (or OLN) equilibria are more conservationist than Markov perfect Nash (or MPN) equilibria.

An alternative, though not equivalent, way of comparing the outcomes of OLN equilibria with MPN equilibria is via the introduction of a depreciation rate. This is examined in Section 3, where we consider a game $G$ with a depreciation rate $\beta$. We show that for every MPN equilib- 
rium with linear strategies, there exists a corresponding OLN equilibrium of a game $\tilde{G}$ with a depreciation rate $\tilde{\beta}$ (equal $\beta$ plus a constant), such that the ratio of the control to the state variable along this OLN equilibrium path is identical to the ratio of the control to the state variable in the MPN equilibrium. Again, in the context of a resource depletion game, the interpretation is that OLN equilibria are more conservationist than the MPN equilibria.

In Section 4, we show that under certain assumptions, the converse of the result reported in Section 2 can be proved. Starting from an openloop equilibrium of a game $G$, we can construct a MPN equilibrium of a corresponding game $\tilde{G}$. This result can be helpful when one searches for MPNE of some game $\tilde{G}$, because in general it is easier to compute an open-loop equilibrium.

\section{THE MODEL}

We consider a continuous time differential game with $N$ players. Let $c_{i} \in R^{m}$ denote the vector of control variables for player $i$. Let $s \in$ $R_{+}^{n}$ denote the vector of state variables. The evolution of the state variables is governed by the following transition equations, written in vector notation,

$$
\dot{s}=g\left(s, c_{1}, \cdots, c_{N}\right)=g(s, c)
$$

where $c=\left(c_{1}, \cdots, c_{N}\right)$. Each player has a utility function

$$
u_{i}=f^{i}\left(s, c_{1}, \cdots, c_{N}\right)=f_{i}(s, c)
$$

and his payoff is:

$$
J_{i}=\int_{0}^{\infty} f^{i}\left(s, c_{1}, \cdots, c_{N}\right) D_{i}(t) d t
$$

where $D_{i}(t)=\exp \left(-r_{i} t\right)$, and $r_{i}$ is a positive number representing player $i$ 's rate of discount.

The control variables must be chosen to satisfy a set of constraints:

$$
h\left(s, c_{1}, \cdots, c_{N}\right) \geq 0
$$

These inequalities may be simply non-negativity constraints on the controls, or more generally technological or institutional restrictions. For example, in a common property resource model, one may want to specify that the sum of extraction rates must not exceed a maximum available flow which is a linear function of the stock. (This specification would also ensure that extractions are zero when the stock is exhausted.) 
A Markovian strategy for player $i$ is a function $m_{i}$ that determines for each pair $(s(t), t)$ the value of the control vector $c_{i}(t)$. A Markovian strategy that does not contain $s(t)$ as an argument is called an open-loop strategy. We will use the supercript 0 to denote an open-loop strategy. Given the initial stock $s(0)$, a profile of open-loop strategies $\prec m_{1}^{0}, \cdots, m_{N}^{0} \succ$, denoted by $m^{0}$, is said to be feasible if the constraints $h\left(s, c_{1}, \cdots, c_{N}\right) \geq 0$ are satisfied for all $t$. The payoff to player $i$ under this profile is denoted $J_{i}\left(s(0), m^{0}\right)$. Let $\prec m_{-i}^{0}, \tilde{m}_{i}^{0} \succ$ denote an alternative open-loop profile constructed from $m^{0}$ by replacing $m_{i}^{0}$ with $\tilde{m}_{i}^{0}$. The profile $m^{0}$ is said to be an open-loop Nash equilibrium given $s(0)$ if no player $i$ can find an alternative feasible profile $\prec m_{-i}^{0}, \tilde{m}_{i}^{0} \succ$ such that his payoff is improved, that is, such that $J_{i}\left(s(0), \prec m_{-i}^{0}, \tilde{m}_{i}^{0} \succ\right)>$ $J_{i}\left(s(0), m^{0}\right)$. It is well known that open-loop Nash equilibria are timeconsistent, in the sense that at any time $\tau \geq 0$, given that all players have followed their open-loop strategies, no player has an incentive to deviate from his strategy. Open-loop Nash equilibria are however not subgame perfect. That is, if for some reason some player $j$ has deviated from his strategy, so that the actual value of $s(\tau)$ is different from the one predicted by player $i$ who initially assumed that no deviation would occur, then in general it will no longer be in player $i$ ' s interest to continue playing his original strategy. For this reason, the predictive power of open-loop Nash equilibria has been seriously questioned. Such equilibria are credible only if all players can commit themselves from the start to stick to their open-loop strategies.

The apparent weakness of the concept of open-loop Nash equilibrium has led economists to favour the concept of Markov perfect Nash equilibrium. (See Fudenberg and Tirole(1991, Chapter 13) for a comprehensive review.) A profile of Markovian strategies $m=\prec m_{1}, \cdots, m_{N} \succ$ is said to be a Markov perfect Nash (MPN) equilibrium if at any time $\tau \geq t$, given any valued $s(\tau)$ which is feasible under the initial condition $s(0)$,no player $i$ can find an alternative feasible strategy $\tilde{m}_{i}$ that would yield him a better payoff for the remaining portion of the game, given that all other players stick to their original Markovian strategies.

Given that all the functions $f^{i}, g$ and $h$ do not depend on $t$ explicitly, it is reasonable to focus on Markov perfect Nash equilibria that consist of strategies that are time-independent. Such strategies are called stationary Markovian strategies. The following result, proved in Long and Shimomura (1995), will be useful:

Proposition 1. If $f^{i}$ is homogeneous of degree $\alpha_{i} \leq 1$, and if both $g$ and $h$ are homogeneous of degree one in $(s, c)$ then player $i$ 's best reply to stationary Markovian strategies that are homogeneous of degree one 
in $s$ is itself stationary and homogeneous of degree one in $s$, and his payoff $J_{i}$ is homogeneous of degree $\alpha_{i}$ in $s$.

Note that the above proposition does not assert existence, which is a quite different matter. In what follows, we attempt to relate MPN equilibria to OLN equilibria. We adopt the following assumptions which are more restrictive than those stated in Proposition 1.

Assumption A1: $f^{i}\left(s, c_{1}, \ldots, c_{N}\right)$ is concave and homogenous of degree $\alpha_{i}$ in $\left(s, c_{1}, \ldots, c_{N}\right)$ and $0<\alpha_{i}<1$

Assumption A2: There is only one state variable, denoted by $s$, $(s \geq 0)$.

Assumption A3: $g\left(s, c_{1}, \ldots, c_{N}\right)$ and $h\left(s, c_{1}, \ldots, c_{N}\right)$ are concave and homogenous of degree one in $\left(s, c_{1}, \ldots, c_{N}\right)$

We shall refer to this game as Game $G$,and assume that there exists a Markov perfect Nash equilibrium with linear strategies:

$$
c_{i}=\gamma_{i} s
$$

where $\gamma_{i} \in R^{m}$.Given $s(0)$, we can compute the realized time paths $s^{*}(t)$ and $c^{*}(t)$. It would seem natural to ask the following question: if all players were required to play only open-loop strategies, would there be an open-loop Nash equilibrium with a time path for the state variable that lies entirely above $s^{*}(t)$ for all positive $t$ ? That is, can we expect that for any Markov perfect Nash equilibrium of the above game, there exists a more conservationist time path that is supported by open-loop strategies? If the answer to that question is in the affirmative, one may reasonably advocate a government policy that makes open-loop equilibria credible. For example, a policy that prevents players from observing the value of the state variable would do the job.

Instead of asking the above question, it is convenient to phrase the question somewhat differently: Can we modify Game $G$ by adding a suitably chosen constant to the rate of discount of each player, in such a way that the realized time paths $s^{*}(t)$ and $c^{*}(t)$ of the Markov perfect equilibrium of Game $G$ coincide with the open-loop Nash equilibrium of the modified game? We now prepare the groundwork for answering this question.

By definition, if $s^{*}(t)$ and $c^{*}(t)$ are realized time paths of a MPN equilibrium, then for each player $i$, the time path $c_{i}^{*}(t)$ must satisfy the necessary conditions of the following optimal control problem. Find a time path $c_{i}(t)$ that maximizes

$$
J_{i}=\int_{0}^{\infty} f^{i}\left(s, \gamma_{1} s, \cdots, \gamma_{i-1} s, c_{i}, \gamma_{i+1} s, \cdots, \gamma_{N} s\right) D_{i}(t) d t
$$


subject to

$$
\begin{gathered}
\dot{s}=g\left(s, \gamma_{1} s, \cdots, \gamma_{i-1} s, c_{i}, \gamma_{i+1} s, \cdots, \gamma_{N} s\right) \\
s(0)=s_{0} \\
h\left(s, \gamma_{1} s, \cdots, \gamma_{i-1} s, c_{i,} \gamma_{i+1} s, \cdots, \gamma_{N} s\right) \geq 0
\end{gathered}
$$

The Hamiltonian for this problem is:

$$
H_{i}=f^{i}+\mu_{i} g
$$

and the corresponding Lagrangian is:

$$
L_{i}=H_{i}+\pi_{i} h
$$

where $\pi_{i}$ is a non-negative vector of Lagrange multipliers . The necessary conditions are (7), (9), (8), and

$$
\begin{gathered}
\frac{\partial f^{i}}{\partial c_{i}}+\mu_{i} \frac{\partial g}{\partial c_{i}}+\pi_{i} \frac{\partial h}{\partial c_{i}}=0 \\
\pi_{i} h\left(s^{*}, \gamma_{1} s^{*}, \cdots, \gamma_{i-1} s^{*}, c_{i}^{*}, \gamma_{i+1} s^{*}, \cdots, \gamma_{N} s^{*}\right)=0 \\
\dot{\mu}_{i}=r_{i} \mu_{i}-\frac{\partial f^{i}\left(s^{*}, c^{*}\right)}{\partial s}-\mu_{i} \frac{\partial g\left(s^{*}, c^{*}\right)}{\partial s}-\pi_{i} \frac{\partial h\left(s^{*}, c^{*}\right)}{\partial s}-\rho_{i}
\end{gathered}
$$

where $\rho_{i}$ is defined as

$$
\rho_{i}=\sum_{j \neq i} \gamma_{j}\left(\frac{\partial f^{i}\left(s^{*}, c^{*}\right)}{\partial c_{j}}+\mu_{i} \frac{\partial g\left(s^{*}, c^{*}\right)}{\partial c_{j}}+\pi_{i} \frac{\partial h\left(s^{*}, c^{*}\right)}{\partial c_{j}}\right)
$$

In addition, we assume that the usual transversality conditions are satisfied:

$$
\begin{gathered}
\lim _{t \rightarrow \infty} \exp \left(-r_{i} t\right) \mu_{i}(t) s^{*}(t)=0 \\
\lim _{t \rightarrow \infty} \exp \left(-r_{i} t\right) \mu_{i}(t) \geq 0
\end{gathered}
$$

Let $\gamma=\left(\gamma_{1}, \cdots, \gamma_{N}\right)$. Since $c_{i}=\gamma_{i} s$ and all the partial derivatives in (12) are homogeneous of degree zero in $(s, c)$, clearly $\rho_{i}$ can be expressed as:

$$
\rho_{i}=\sum_{j \neq i} \gamma_{j}\left(\frac{\partial f^{i}(1, \gamma)}{\partial c_{j}}+\mu_{i} \frac{\partial g(1, \gamma)}{\partial c_{j}}+\pi_{i} \frac{\partial h(1, \gamma)}{\partial c_{j}}\right)
$$


In the special case where the constraint (9) is not binding and where each player's utility function does not have other players's control variables as arguments, then

$$
-\frac{\rho_{i}}{\mu_{i}}=-\sum_{j \neq i} \gamma_{j} \frac{\partial g(1, \gamma)}{\partial c_{j}} \equiv \theta_{i}
$$

We are now ready to state our main result

Proposition 2. Let $c_{i}=\gamma_{i} s$ for $i=1, \cdots, N$ be a MPN equilibrium strategy profile for the game $G$ where player $i$ 's discount rate is $r_{i}$ and let $s^{*}(t)$ and $c^{*}(t)$ be the resulting equilibrium time paths of the state and control variables. Then $c^{*}(t)$ is an open-loop Nash equilibrium for a modified game $\hat{G}$ which would be identical to $G$ except that for each player the discount rate is now $r_{i}+\theta_{i}$, where $\theta_{i}$ is given by (16). This equivalence holds under the assumptions that (i) A1, A2, and $\mathbf{A 3}$ hold, (ii) the constraint $h$ is not binding, (iii) each player's utility function depends only on the state variable and his control variables, (iv) the transversality conditions (13) and (14) are satisfied.

Proof : Substitute (16) into (11). The resulting equation, together with (10), (13), (7), (9), and (8), are necessary and sufficient for an open-loop Nash equilibria.

Remark 1: If $\frac{\partial g}{\partial c_{i}}$ is negative for all $c_{i}$, then we may interprete the control variables as extraction rates and the state variable as a stock of resource, and call the game a Common Access Resource Game. In this case we would expect all $\gamma_{i}$ to be positive and therefore $\mu_{i}$ would be positive. It follows that a MPN equilibrium of a common property game $G$ yields an equilibrium play that is identical to that given by an OLN equilibrium of a related game $\hat{G}$ where each player has a higher rate of discount. In this sense, MPN equilibria are less conservationist than OLN equilibria.

\footnotetext{
Example 1:A common pool problem with heterogeneous players.

Let $s$ denote a stock of natural resource exploited by $N$ players with different rates of discount $\left(r_{i} \neq r_{j}\right)$ and different utility functions.We specify the functions $g$ and $f_{i}$ as follows:
}

$$
g(s, c)=a s-\sum_{i=1}^{N} c_{i}
$$


and $f_{i}(s, c)=c_{i}^{\alpha_{i}}$ where $\alpha_{i} \in(0,1), r_{i} \geq a \geq 0$,and each $c_{i}$ is a nonnegative real number. First let us check that there exists a unique MPN equilibrium in linear strategies. Let $\mu_{i}$ denote the costate variable, and assume an interior solution. The necessary conditions for player $i$ 's control problem are

$$
\begin{aligned}
\alpha_{i} c_{i}^{\alpha_{i}-1} & =\mu_{i} \\
\dot{\mu}_{i} & =r_{i} \mu_{i}-a \mu_{i}+\mu_{i} \sum_{j \neq i} \frac{\partial c_{i}}{\partial s} \\
\dot{s} & =a s-\sum_{i=1}^{N} c_{i}
\end{aligned}
$$

Substituting $c_{j}=\gamma_{j} s$, we have

$$
\begin{gathered}
\alpha_{i}\left(\gamma_{i} s\right)^{\alpha_{i}-1}=\mu_{i} \\
\dot{\mu}_{i}=\mu_{i}\left(r_{i}-a+\sum_{j \neq i} \gamma_{j}\right) \\
\dot{s}=s\left(a-\sum_{i=1}^{N} \gamma_{j}\right)
\end{gathered}
$$

Equation (17) yields

$$
-\left(1-\alpha_{i}\right) \frac{\dot{s}}{s}=\frac{\dot{\mu}_{i}}{\mu_{i}}
$$

Substituting (18) and (19) into (20), we obtain

$$
r_{i}-\alpha_{i} a=\left(1-\alpha_{i}\right) \gamma_{i}-\alpha_{i} \sum_{j \neq i} \gamma_{j}
$$

Since the preceeding equation must hold for all $i$, we have the matrix equation

$$
\left(\begin{array}{llll}
1-\alpha_{1} & -\alpha_{1} & \ldots & -\alpha_{1} \\
-\alpha_{2} & 1-\alpha & \ldots & -\alpha_{2} \\
\cdots & \ldots & \cdots & \cdots \\
-\alpha_{N} & -\alpha_{N} & \cdots & 1-\alpha_{N}
\end{array}\right)\left(\begin{array}{c}
\gamma_{1} \\
\gamma_{2} \\
\cdots \\
\gamma_{N}
\end{array}\right)=\left(\begin{array}{r}
r_{1}-a \alpha_{1} \\
r_{2}-a \alpha_{2} \\
\cdots \\
r_{N}-a \alpha_{N}
\end{array}\right)
$$

Clearly if $\sum \alpha_{i}$ is less than unity and $a \alpha_{i}$ is less than $r_{i}$ then this matrix equation has a unique and positive solution $\left(\gamma_{1}, \cdots, \gamma_{N}\right)$. (See Takayama(1985, Theorem 4.C.4).) Finally, it is easy to check that the transversality conditions (13) and (14) are satisfied, because $\frac{d \ln \left(s \mu_{i} \exp \left(-r_{i} t\right)\right)}{d t}=-\gamma_{i}$. 


\section{An Alternative Formulation}

We now introduce an alternative way of comparing MPN equilibria and OLN equilibria. Instead of thinking in terms of an adjustment to the discount rate, let us modify game $G$ by adding a natural rate of depreciation of the stock. Recall that in game $G$, the state variable is $s$, and $\dot{s}=g(s, c)$, where $c=\left(c_{1}, \cdots, c_{N}\right)$, and $c_{i}$ is a vector of $m$ control variables, and $s$ is a real number. Consider an alternative environment $\tilde{G}$ in which the state variable is subject to an additional decay. To avoid possible confusion, in this environment the state variable is denoted by $y$, and the vector of control variables for player $i$ is denoted by $a_{i}$. We assume $\dot{y}=g(y, a)-\delta y$, where $\delta$ is the rate of decay. The utility function of player $i$ is $f\left(y, a_{i}\right)$, where $f$ is homogeneous of degree $\alpha, \alpha \in(0,1)$. In addition we assume that all players have the same rate of discount, $r$ , and the functional form of $f$ is the same for all $i$. For simplicity, the constraints on the control variables are just non-negativity constraints. The following result is quite analogous to Proposition 2. The assumptions (i) through (iv) of Proposition 2 are maintained in the following Proposition as well.

Proposition 3. Assume that Game $G$ has a symmetric MPN equilibrium with linear strategies $c_{i}=\gamma_{i} s$, where $\gamma_{i}=\left(\gamma_{i 1}, \cdots, \gamma_{i m}\right)$ and $\gamma_{i}=\gamma_{j}$ for all players $i, j=1, \cdots, N$. Denote the resulting time paths of the control and state variables by $c_{i}^{*}(t)$ and $s^{*}(t)$. Define

$$
\delta=\frac{(1-N)}{\alpha} \sum_{k=1}^{m} \gamma_{i k} \frac{\partial g\left(1, \gamma_{1}, \cdots, \gamma_{N}\right)}{\partial c_{i k}}
$$

Consider now a corresponding game $\tilde{G}$ in which the transition equation for the state variable is $\dot{y}=g(y, a)-\delta y$, where $\delta$ is given by equation (23). Then we can construct for the game $\tilde{G}$ an open-loop Nash equilibrium $a_{i}^{0}(t)$ and the resulting time path for the state variable, $y^{0}(t)$, by using $c_{i}^{*}(t)$ and $s^{*}(t)$ :

$$
\begin{aligned}
& a_{i}^{0}(t)=c_{i}^{*}(t) \exp (-\delta t) \\
& y^{0}(t)=s^{*}(t) \exp (-\delta t)
\end{aligned}
$$

It follows that the ratio $\frac{a_{i}^{0}(t)}{y^{0}(t)}$ for game $\tilde{G}$ is equal to the ratio $\frac{c_{i}^{*}(t)}{s^{*}(t)}$ for the original game $G$.

Remark 2: For games with common access resources, Remark 1 of the 
preceeding section applies here, so we expect $\delta$ to be positive. Then Proposition 2 may be interpreted as implying that MPN equilibria are less conservationist than OLN ones in the sense that despite a higher rate of decay in game $\tilde{G}$, the ratio of consumption to stock in the OLN equilibrium of this game is the same as that of the MPN equilibrium of the original game $G$.

Proof: To find an open-loop solution for the game $\tilde{G}$, we form the Hamiltonian

$$
H_{i}=f\left(y, a_{i}\right)+\lambda_{i}\left[g\left(y, a_{1}, \cdots, a_{N}\right)-\delta y\right]
$$

The necessary conditions are

$$
\begin{gathered}
\frac{\partial f\left(y, a_{i}^{0}\right)}{\partial a_{i}}=-\lambda_{i} \frac{\partial g\left(y, a_{1}^{0}, \cdots, a_{N}^{0}\right)}{\partial a_{i}} \\
\dot{\lambda}_{i}=\lambda_{i}(r+\delta)-\frac{\partial f\left(y, a_{i}\right)}{\partial y}-\lambda_{i} \frac{\partial g\left(y, a_{1}, \cdots, a_{N}\right)}{\partial y} \\
\dot{y}=g\left(y, a_{1}, \cdots, a_{N}\right)-\delta y
\end{gathered}
$$

and the transversality conditions are

$$
\begin{gathered}
\lim _{t \rightarrow \infty} \lambda_{i} \exp (-r t) \geq 0 \\
\lim _{t \rightarrow \infty} \lambda_{i} \exp (-r t) y(t)=0
\end{gathered}
$$

Now by assumption the original game $G$ has a symmetric MPN equilibrium, with $c_{i}=\gamma_{i} s$. Therefore for player $i$, there exists a time path of the costate variable associated with $s^{*}(t)$,denoted by $\mu_{i}(t)$, such that the following conditions hold (where for all $j \neq i, c_{j}^{*}$ stands for $\gamma_{j} s^{*}$ ):

$$
\begin{gathered}
\frac{\partial f\left(s^{*}, c_{i}^{*}\right)}{\partial c_{i}}=-\mu_{i} \frac{\partial g\left(s^{*}, c_{1}^{*}, \cdots, c_{N}^{*}\right)}{\partial c_{i}} \\
\dot{\mu}_{i}=\mu_{i} r-\frac{\partial f\left(s^{*}, c_{i}^{*}\right)}{\partial s}-\mu_{i} \frac{\partial g\left(s^{*}, c_{1}^{*}, \cdots, c_{N}^{*}\right)}{\partial s}-\mu_{i} \sum_{j \neq i} \gamma_{j} \frac{\partial g\left(s^{*}, c_{1}^{*}, \cdots, c_{N}^{*}\right)}{\partial c_{j}} \\
\dot{s}^{*}=g\left(s^{*}, c_{1}^{*}, \cdots, c_{N}^{*}\right) \\
\lim _{t \rightarrow \infty} \mu_{i} \exp (-r t) \geq 0 \\
\lim _{t \rightarrow \infty} \mu_{i} \exp (-r t) s^{*}(t)=0
\end{gathered}
$$

Let us define

$$
\lambda_{i}(t) \equiv \mu_{i}(t) \exp ((1-\alpha) \delta t)
$$




$$
\begin{gathered}
a_{i}(t) \equiv c_{i}^{*}(t) \exp (-\delta t) \\
y(t) \equiv s^{*}(t) \exp (-\delta t)
\end{gathered}
$$

Substituting these variables into (30), (31), and (32), and using the fact that the partial derivatives of $f$ are homogeneous of degree $\alpha-1$, and the partial derivatives of $g$ are homogeneous of degree zero, we obtain the conditions (25), (26), and (27). Furthermore, conditions (33) and (34) imply that the transversality conditions (28) and (29) are satisfied provided that $r+2 \delta$ is positive. It follows that by construction we have found an OLN equilibrium for the game $\tilde{G}$. $\square$

Example 2: Exploitation of a resource stock when utility depends on both stock and flow.

Let $s$ be a common property resource and $c_{i}$ be player $i$ 's rate of extraction ( a non-negative real number). Assume $\dot{s}=-\sum_{i=1}^{N} c_{i}$. Player $i$ maximizes the integral of discounted utility

$$
\int_{o}^{\infty}\left(s c_{i}\right)^{\alpha / 2} \exp (-r t) d t
$$

where $r>0$, and $N \alpha<2$. It is easy to verify that the following strategy for all players constitutes a MPN equilibrium:

$$
c_{i}=\frac{r s}{2-N \alpha}
$$

This yields the realized time paths

$$
\begin{gathered}
s^{*}(t)=s(0) \exp \left(\frac{-r N t}{2-N \alpha}\right) \\
c_{i}^{*}(t)=\frac{r s(0)}{2-N \alpha} \exp \left(\frac{-r N t}{2-N \alpha}\right)
\end{gathered}
$$

Now let us consider a modified game, denoted by $\tilde{G}$, where the state variable is $y$, the extraction rates are $a_{i}, i=1, \cdots, N$, where $a_{i}$ is a real number, and there is a decay rate $\delta$, so that $\dot{y}=-\delta y-\sum_{i=1}^{N} a_{i}$. Applying Proposition 3, we claim that if $\delta=\left(\frac{N-1}{\alpha}\right)\left(\frac{r}{2-N \alpha}\right)$ then the following time paths of the control variable $a_{i}(i=1, \cdots, N)$, constitute an OLN equilibrium:

$$
a_{i}(t)=\frac{r y(0)}{2-N \alpha} \exp \left(\frac{-r N}{2-N \alpha}-\delta\right) t
$$

The resulting time path of the state variable is

$$
y(t)=y(0) \exp \left(\frac{-r N}{2-N \alpha}-\delta\right) t
$$


The ratio $a_{i}(t) / y(t)$ is thus equal to the ratio $c_{i}(t) / s(t)$ in the MPN equilibrium of the original game $G$. Finally, for the OLN equilibrium of game $\tilde{G}$, the time path of the co-state variable is

$$
\lambda_{i}(t)=\frac{\alpha}{2}\left[a_{i}(t) y(t)\right]^{\alpha / 2} a_{i}(t)^{-1}
$$

It satisfies the condition

$$
\dot{\lambda}_{i}(t)=(r+\delta) \lambda_{i}-\frac{\alpha}{2}\left(a_{i} y\right)^{\alpha / 2} y^{-1}
$$

The transversality conditions are also satisfied.

\section{A Converse Result}

In this Section we seek to prove the converse of Proposition 2. Here we begin with an OLN equilibrium of a certain game $G$, and use it to construct aMPN equilibrium of a corresponding game $\tilde{G}$. We hope that this result is a useful beginning step for the search of MPN equilibria, because OLN equilibria are typically easier to find.

Let us consider the problem of finding an OLN equilibrium for a game $G$ where player $i$ 's seeks a time path $c_{i}(t)$ that maximizes

$$
\int_{0}^{\infty} f^{i}\left(s, c_{1}, \ldots, c_{N}\right) \exp \left(-r_{i} t\right) d t, \quad i=1, \ldots, N
$$

subject to

$$
\begin{gathered}
\dot{s}=g\left(s, c_{1}, \ldots, c_{N}\right), \quad s(0)=s_{0} \\
h\left(s, c_{1}, \ldots, c_{N}\right) \geq 0
\end{gathered}
$$

Player $i$ takes the time paths $c_{j}(t)$ as given for all $j \neq i$. The assumptions $\mathrm{A} 1, \mathrm{~A} 2$, and $\mathrm{A} 3$ are maintained.

Consider the following system of equations

$$
\begin{gathered}
\frac{\partial f^{i}\left(1, \gamma_{1}, \ldots, \gamma_{N}\right)}{\partial c_{i}}+\mu_{i} \frac{\partial g\left(1, \gamma_{1}, \ldots, \gamma_{N}\right)}{\partial c_{i}}=0 \quad i=1, \ldots, N \\
r_{i} \mu_{i}-\frac{\partial f^{i}\left(1, \gamma_{1}, \ldots, \gamma_{N}\right)}{\partial s}-\mu_{i} \frac{\partial g\left(1, \gamma_{1}, \ldots, \gamma_{N}\right)}{\partial s}+\left(1-\alpha_{i}\right) \mu_{i} g\left(1, \gamma_{1}, \ldots, \gamma_{N}\right)=0
\end{gathered}
$$

(also, $i=1, \ldots, N)$, where $\mu_{i}$ and $\gamma_{i}(i=1, \ldots, N)$, are unknowns.

Assumption 4: The system of equations (37) and (38) has a solution $\left(\mu_{1}^{*}, \ldots, \mu_{N}^{*}, \gamma_{1}^{*}, \ldots, \gamma_{N}^{*}\right)$ where $\mu_{i}^{*} \geq 0, i=1, \ldots, N$. 
Assumption 5: $h\left(1, \gamma_{1}^{*}, \ldots, \gamma_{N}^{*}\right)>0$ and $r_{i}>\left(2-\alpha_{i}\right) g\left(1, \gamma_{1}^{*}, \ldots, \gamma_{N}^{*}\right)$

Let $s^{*}(t)$ be the solution of the differential equation

$$
\dot{s}=g\left(s, \gamma_{1}^{*} s, \ldots, \gamma_{N}^{*} s\right), \quad s(0)=s_{0}
$$

Then

$$
s^{*}(t)=s_{0} \exp \left[g\left(1, \gamma^{*}\right) t\right]
$$

Lemma 1: Assume A1-A5 hold. The following time paths for the control variables constitute an OLNE for the game $G$.

$$
c_{i}^{*}(t)=\gamma_{i}^{*} s^{*}(t)=s_{0} \exp \left[g\left(1, \gamma^{*}\right) t\right]
$$

Proof: Define $\lambda_{i}^{*}=\left[s^{*}\right]^{\alpha_{i}-1} \mu_{i}^{*}$. It is easy to verify that the following sufficient conditions of an OLN equilibrium are satisfied:

$$
\begin{gathered}
H_{i}=f^{i}\left(s, c_{1}, \ldots, c_{N}\right)+\lambda_{i}^{*} g\left(s, c_{1}, \ldots, c_{N}\right) \\
\frac{\partial H_{i}}{\partial c_{i}}=0 \\
\dot{\lambda}_{i}^{*}=r_{i} \lambda_{i}^{*}-\frac{\partial H_{i}}{\partial s} \\
\lim _{t \rightarrow \infty} \lambda_{i}^{*}(t) \exp \left(-r_{i} t\right) \geq 0 \\
\lim _{t \rightarrow \infty} \lambda_{i}^{*}(t) \exp \left(-r_{i} t\right) s^{*}(t)=0
\end{gathered}
$$

(notice that $\dot{s} / s=g\left(1, \gamma_{1}^{*}, \ldots, \gamma_{N}^{*}\right.$ )

and therefore

$\left.\dot{\lambda}_{i} / \lambda_{i}=\left(1-\alpha_{i}\right) g\left(1, \gamma_{1}^{*}, \ldots, \gamma_{N}^{*}\right).\right) \square$

We now show that there exists discount rates $\hat{r}_{i}(i=1, \ldots, N)$ such that the strategies $c_{i}(s)=\gamma_{i}^{*} s(i=1, \ldots, N)$ constitute a MPN equilibrium for a modified differential game $\tilde{G}$ which corresponds to the initial game $G$ except for the modified discount rates.

First, in view of $(37), c_{i}(s) \equiv \gamma_{i}^{*} s$ is the maximizer of the Hamiltonian

$H_{i}^{*}=f^{i}\left(s, \gamma_{1}^{*} s, \ldots, \gamma_{i-1}^{*} s, c_{i}, \gamma_{i+1}^{*}, \ldots, \gamma_{N}^{*}\right)+\lambda_{i}^{*} g\left(s, \gamma_{1}^{*} s, \ldots, \gamma_{i-1}^{*} s, c_{i}, \gamma_{i+1}^{*}, \ldots, \gamma_{N}^{*}\right)$

where

$$
\lambda_{i}^{*} \equiv \mu_{i}^{*} s^{\alpha_{i}-1}
$$


Now, assume that $f^{i}$ is a function of $s$ and $c_{i}$ only. Then, if $\lambda_{i}^{*}$ and $s$ satisfy

$$
\dot{\lambda}_{i}^{*}=\hat{r}_{i} \lambda_{i}^{*}-f_{s}^{i}\left(s, c_{i}\right)-\lambda_{i}^{*} g_{s}(s, \gamma s)-\lambda_{i}^{*} \sum_{j \neq i} \gamma_{j}^{*} g_{j}\left(s, \gamma^{*} s\right)
$$

and

$$
\dot{s}=s g\left(1, \gamma^{*}\right)
$$

where $\gamma^{*}$ denotes the vector $\left(\gamma_{1}^{*}, \ldots, \gamma_{N}^{*}\right)$, then $c_{i}(s)=\gamma_{i}^{*} s, i=1, \ldots N$, are MPN strategies for the game $\tilde{G}$. We now verify that (42) is indeed satisfied. In view of (41), condition (42) can be written as

$$
\dot{\lambda}_{i}^{*}=\lambda_{i}^{*}\left[\hat{r}_{i}-\left(\lambda_{i}^{*}\right)^{-1} f_{s}^{i}\left(1, \gamma_{i}^{*}\right) s^{\alpha_{i}-1}-g_{s}\left(1, \gamma^{*}\right)-\sum_{j \neq i} \gamma_{j}^{*} g_{j}\left(1, \gamma^{*}\right)\right]
$$

or

$$
\dot{\lambda}_{i}^{*}=\lambda_{i}^{*}\left[\hat{r}_{i}-\left(\mu_{i}^{*}\right)^{-1} f_{s}^{i}\left(1, \gamma_{i}^{*}\right)-g_{s}\left(1, \gamma^{*}\right)-\sum_{j \neq i} \gamma_{j}^{*} g_{j}\left(1, \gamma^{*}\right)\right]
$$

Since $\mu_{i}^{*}$ is time-invariant by $\mathbf{A} 4,(41)$ gives $\dot{\lambda}_{i}^{*} / \lambda_{i}^{*}=\left(\alpha_{i}-1\right) \dot{s} / s=$ $\left(\alpha_{i}-1\right) g\left(1, \gamma^{*}\right)$. Therefore (44) holds if and only if

$$
\left(\alpha_{i}-1\right) g\left(1, \gamma^{*}\right)=\hat{r}_{i}-\left(\mu_{i}^{*}\right)^{-1} f_{s}^{i}\left(1, \gamma_{i}^{*}\right)-g_{s}\left(1, \gamma^{*}\right)-\sum_{j \neq i} \gamma_{j}^{*} g_{j}\left(1, \gamma^{*}\right)
$$

In view of (38), condition (45) holds if and only if

$$
\hat{r}_{i}=r_{i}+\sum_{j \neq i} \gamma_{j}^{*} g_{j}\left(1, \gamma^{*}\right) \equiv r_{i}-\theta_{i}
$$

We have thus proved the following proposition:

Proposition 4: Under Assumptions A1-A5, the differential game $G$ has the following OLN solution

$$
c_{i}(t)=\gamma_{i}^{*} s_{0} \exp \left[g\left(1, \gamma^{*}\right) t\right], \quad i=1, \ldots, N
$$

and the evolution of the state variable along the equilibrium play is

$$
s(t)=s_{0} \exp \left[g\left(1, \gamma^{*}\right) t\right]
$$

Consider the modified game $\tilde{G}$ which would be identical to $G$ except that for each player the discount rate is now $r_{i}-\theta_{i}$. Then, under the additional assumption that each player's utility function depends only on the state variable and his control variables, this modified game has a MPN equilibrium where player $i$ 's strategy is $c_{i}(s)=\gamma_{i}^{*} s, i=1, \ldots, N$. 


\section{Concluding remarks}

Propositions 2, 3 and 4 can be easily extended to accommodate the case where the integrand is the logarithmic function. Recall that if $f^{i}$ is homogenous of degree $\alpha_{i}$ then marginal utility is homogenous of degree $\alpha_{i}-1$. In the case of a logarithmic utility function, marginal utility is homogenous of degree -1 . It follows that the only modification is we must replace $\alpha_{i}$ by 0 . The linear policy function $c_{i}=\gamma_{i} s$ remains applicable, because, as shown in Long and Shimomura (1995), the best reply to a linear strategy is also linear when the utility function is logarthmic. 


\section{References}

[1] Clemhout, Simone and Henry Wan, Jr. (1995), "Differential GamesEconomic Applications," in R.J.Aumann and S.Hart (eds.), Handbook of Game Theory, Volume 2, Elsevier Science Publishers, New York.

[2] Fudenberg, Drew and Jean Tirole (1991), Game Theory, MIT Press, Cambridge, Mass.

[3] Long, Ngo Van and Koji Shimomura (1995),“ Some Results on Markov Equilibria of a Class of Homogeneous Differential Games," Cahier Scientifique 95s-36, CIRANO, Montreal. (to appear in Journal of Economic Behavior and Organization.

[4] Takayama, Akira (1985), Mathematical Economics, Second Edition, Cambridge University Press, New York. 


\section{Liste des publications au CIRANO .}

\section{Cahiers CIRANO / CIRANO Papers (ISSN 1198-8169)}

96c-1 Peut-on créer des emplois en réglementant le temps de travail ? / par Robert Lacroix

95c-2 Anomalies de marché et sélection des titres au Canada / par Richard Guay, JeanFrançois L'Her et Jean-Marc Suret

95c-1 La réglementation incitative / par Marcel Boyer

94c-3 L'importance relative des gouvernements : causes, conséquences et organisations alternative / par Claude Montmarquette

94c-2 Commercial Bankruptcy and Financial Reorganization in Canada / par Jocelyn Martel

94c-1 Faire ou faire faire : La perspective de l'économie des organisations / par Michel Patry

\section{Série Scientifique / Scientific Series (ISSN 1198-8177)}

97s-22 Comparing Open-Loop with Markov Equilibria in a Class of Differential Games / Ngo Van Long, Koji Shimomura et Harataka Takahashi

97s-21 Efficiency Inducing Taxation for Polluting Oligopolists / Hassan Benchekroun et Ngo Van Long

97s-20 Tests of Conditional Asset Pricing Models in the Brazilian Stock Market / Marc Bonomo et René Garcia

97s-19 Nonparametric Methods and Option Pricing / Eric Ghysels, Valentin Patilea, Éric Renault et Olivier Torrès

97s-18 A vailability and Accuracy of Accounting and Financial Data in Emerging Markets: The Case of Malaysia / Jean-Marc Suret, Cameron Morrill et Janet Morrill

97s-17 L'évolution des structures financières des grandes entreprises canadiennes / Jean-Marc Suret et Jean-François L'Her

97s-16 Le régime d'épargne-actions du Québec : Vue d'ensemble et évaluation / Jean-Marc Suret et Élise Cormier

97s-15 Liberalization, Political Risk and Stock Market Returns in Emerging Markets / Jean-Marc Suret, Jean-François L'Her

97s-14 Methods of Pay and Earnings: A Longitudinal Analysis / Daniel Parent

97s-13 A Note on Hedging in ARCH and Stochastic Volatility Option Pricing Models / René Garcia et Éric Renault

97s-12 Equilibrium Asset Prices and No-Arbitrage with Portfolio Constraints / Jérôme B. Detemple et Shashidhar Murthy

97s-11 Aggregation, Efficiency and Mutual Fund Separation in Incomplete Markets / Jérôme B. Detemple et Piero Gottardi

- Vous pouvez consulter la liste complète des publications du CIRANO et les publications elles-mêmes sur notre site World Wide Web à l'adresse suivante :

http://www.cirano.umontreal.ca/publication/page1.htm 